\title{
Physico-mechanical properties of chitosan films with carvacrol and grape seed extract
}

\author{
Javiera F. Rubilar ${ }^{\mathrm{a}, \mathrm{c}}$, Rui M.S. Cruz ${ }^{\mathrm{b}, \mathrm{c}}$, Hélder D. Silva ${ }^{\mathrm{d}}$, António A. Vicente ${ }^{\mathrm{d}}$, Igor Khmelinskii ${ }^{\mathrm{a}, \mathrm{c}}$, \\ Margarida C. Vieira ${ }^{\mathrm{b}, \mathrm{c}, *}$ \\ a Departamento de Química e Farmácia, Faculdade de Ciências e Tecnologia, Universidade do Algarve, Campus de Gambelas, 8005-139 Faro, Portugal \\ ${ }^{\mathrm{b}}$ Departamento de Engenharia Alimentar, Instituto Superior de Engenharia, Universidade do Algarve, Campus da Penha, 8005-139 Faro, Portugal \\ ' Centro de Investigação em Química do Algarve (CIQA), Departamento de Química e Farmácia, Faculdade de Ciências e Tecnologia, Universidade do Algarve, \\ Campus de Gambelas, 8005-139 Faro, Portugal \\ ${ }^{\mathrm{d}}$ IBB - Institute for Biotechnology and Bioengineering, Centre for Biological Engineering, Universidade do Minho, Campus de Gualtar, 4710-057 Braga, Portugal
}

\section{A R T I C L E I N F O}

Article history:

Available online 16 July 2012

\section{Keywords:}

Physico-mechanical properties

Carvacrol

Grape seed extract

Chitosan films

\begin{abstract}
A B S T R A C T
The physico-mechanical properties of 3 films composed by carvacrol, grape seed extract (GSE) and chitosan in different proportions were studied. The films, prepared by solvent casting technique with the following compositions of the casting solutions in carvacrol, GSE and chitosan: film-1: 9.6 ppm-684 ppm-1.25\% w/v, film-2: 60 ppm-400 ppm-1.2\% w/v and film-3: 90 ppm-160 ppm-1.24\% $\mathrm{w} / \mathrm{v}$ and were compared to a control $(1.25 \% \mathrm{w} / \mathrm{v}$ chitosan) film. Mechanical, structural, barrier and colour properties of the films were evaluated. Film-3 presented the lowest water vapour and carbon dioxide permeabilities ( $W V P$ and $\mathrm{CO}_{2} \mathrm{P}$ ) and tensile strength $(T S)$ values and the highest oxygen permeability $\left(\mathrm{O}_{2} \mathrm{P}\right)$, whereas film-1 presented the highest water content and the lowest crystallinity, $\mathrm{CO}_{2} \mathrm{P}$, TS and luminosity. These results suggest that in the range studied, carvacrol and GSE affect the film structure and its mechanical properties due to hydrophilic (GSE) and hydrophobic (carvacrol) compounds. This work will help the development of edible films, based on physico-mechanical properties, contributing to food preservation and shelf-life extension.
\end{abstract}

(ㄷ) 2012 Elsevier Ltd. All rights reserved.

\section{Introduction}

Excessive consumption of plastic materials derived from petroleum and their poor degradation generate a massive accumulation of plastic waste that has been disposed in the environment. For this reason, they have been classified as highly polluting agents (Rodríguez et al., 2012). To avoid this negative impact, the European Union is promoting different strategies to confront this problem. According to the European Directive on Packaging and Packaging Waste the management of packaging and packaging waste should include as a first priority the prevention of packaging waste and, as additional fundamental principles, reuse of packaging, recycling and other forms of recovering packaging waste that allow reducing the final disposal of such wastes. However, these measures have failed to reduce significantly the amount of wastes (Rudnik, 2008). Thus, the use of natural polymers has emerged as an

\footnotetext{
* Corresponding author at: Centro de Investigação em Química do Algarve (CIQA), Departamento de Química e Farmácia, Faculdade de Ciências e Tecnologia, Universidade do Algarve, Campus de Gambelas, 8005-139 Faro, Portugal. Tel.: +351 289 800900/800124; fax: +351289 800066/888405.

E-mail addresses: javiera.rubilar@gmail.com (J.F. Rubilar), rcruz@ualg.pt (R.M.S. Cruz), ikhmelin@ualg.pt (I. Khmelinskii), mvieira@ualg.pt (M.C. Vieira).
}

alternative to face up to this problem. Edible films can help solve the waste disposal problem by partially replacing nonbiodegradable plastics. They can also act as a barrier to external influences such as water vapour and oxygen, as a vehicle for functional compounds, at the same time reducing bruising and breakage and thus preserving/improving food integrity (Martins et al., 2012).

Chitosan is a natural polymer obtained by deacetylation of chitin, which is the major constituent of the exoskeleton of crustaceans. Chitosan has been proved to be nontoxic, biodegradable, and biocompatible, also having intrinsic antimicrobial activity, inhibiting the growth of a wide variety of bacteria (Tripathi et al., 2009). The cationic property of chitosan offers an opportunity to establish electrostatic interactions with other compounds. Due to these characteristics, chitosan has been widely used for the production of edible films (Martins et al., 2012). In addition, chitosan is an excellent edible film component due to its transparent filmforming capacity and good mechanical properties, with application in a variety of packaging needs (Bourbon et al., 2011). Chitosan films are good barriers to gases $\left(\mathrm{CO}_{2}\right.$ and $\mathrm{O}_{2}$ ) (Hosokawa et al., 1990) but present high permeabilities to water vapour. In order to improve water barrier properties of chitosan films, various compounds, such as oleic acid and $\alpha$-tocopherol are frequently incorporated (Park and Zhao, 2004; Vargas et al., 2009). 
Multifunctional packaging systems containing active substances have a high potential for commercial food packaging applications. On the other hand, the permeability of the film depends on its chemical structure and morphology, the nature of permeant and temperature of the environment (Siripatrawan and Harte, 2010). Moreover, the water vapour permeability is the most extensively studied property of edible films because of the importance of water in deteriorative reactions in foods (Martins et al., 2012).

Consumers prefer foods with improved safety; this is particularly relevant in the case of fresh and minimally processed foods using these packaging systems (Lee, 2005). The incorporation of antimicrobial and/or antioxidant compounds of natural origin into chitosan films is an interesting way to enhance chitosan films' functional properties. Several plant essential oils are natural antimicrobial (AM) agents that have a great potential as preservative ingredients, having a wide acceptance by consumers (Burt, 2004). Moreover, they are generally recognized as safe, status defined by FDA (US Food and Drug Administration). The AM components are commonly found in the essential oil fractions and may have a wide spectrum of AM activity (Gutierrez et al., 2009). One of them is carvacrol, a major component (50-86\%) of spices such as oregano (Origanum sp.), which has been used for decades as a food preservative (Kulisic et al., 2004). Carvacrol is a phenolic compound with proven AM activity against bacteria (Guarda et al., 2011; Periago et al., 2004), fungi (Guarda et al., 2011; Daferera et al., 2003) and yeasts (Guarda et al., 2011; Arora and Kaur, 1999), showing a high potential to improve the shelf-life and safety of perishable foods (Holley and Patel, 2005; Martínez-Romero et al., 2007). This compound is hydrophobic and may dissolve in the hydrophobic domain of the cytoplasmic membrane of bacterial cells, between the lipidic acyl chains (Lagouri et al., 1993; Sivropoulou et al., 1996).

Grape seed extract (GSE), a well known AM agent, is a rich source of polyphenolic compounds, mainly monomeric catechins and epicatechin, gallic acid, and polymeric and oligomeric procyanidins (Monagas et al., 2003). These polyphenolic compounds showed various biological effects, including AM capacity (Jayaprakasha et al., 2003; Baydar et al., 2004, 2006; Furiga et al., 2009).

The use of combinations of natural AM agents may increase the spectrum of AM activity, reduce the resistance of microorganisms and may also produce synergistic interactions exhibiting AM activity greater than that of a simple sum of AM agents (Choi et al., 2009) and may also contribute to improve the physico-mechanical properties of the films.

Therefore, the goal of this work was to study the physicomechanical properties of films composed by carvacrol, GSE and chitosan combinations.

\section{Materials and methods}

\subsection{AM compounds and chemicals}

Carvacrol (98\% pure; Cat: 28,219-7), sodium bromide ( $\mathrm{NaBr}$, 02119-1KG) and chitosan (high molecular weight, with a deacetylation degree of $>75 \%$ Cat: 419419-250G) were obtained from Sigma Aldrich (Lisbon, Portugal), GSE (exGrape ${ }^{\circledR}$ seed OPC 40 powder (polyphenols $>95 \%$ and proanthocyanidins $>70 \%$ )) from Gardonnenque (Groupe Grap'Sud, Cruviers Lascours, France). Methanol, acetic acid, glycerol, Tween-80 were purchased from José Manuel Gomes dos Santos (JMGS Odivelas, Portugal).

\subsection{Optimal antimicrobial combination (OAMC)}

Solution with optimized antimicrobial combination were previously designed by simplex centroid mixture design combining carvacrol (0-300 ppm, $\left.X_{1}\right)$, GSE (0-2000 ppm, $\left.X_{2}\right)$ and chitosan $\left(0-2 \% \mathrm{w} / \mathrm{v}, \mathrm{X}_{3}\right)$, using the Design-Expert ${ }^{\circledR} 7.0$ software (DesignExpert, 2005). The optimised solutions (Table 1) showed antimicrobial properties against different spoilage microorganisms (6D reduction, results from Rubilar et al. (2012)). The films were prepared with different mixtures of carvacrol (ppm), GSE (ppm) and chitosan (\% w/v), film-1: $9.6 \mathrm{ppm}-684 \mathrm{ppm}-1.25 \% \mathrm{w} / \mathrm{v}$, film-2: 60 ppm-400 ppm-1.2\% w/v and film-3: 90 ppm-160 ppm$1.24 \% \mathrm{w} / \mathrm{v}$ were compared with control chitosan film (prepared from $1.25 \% \mathrm{w} / \mathrm{v}$ solution).

\subsection{Preparation of chitosan films}

Chitosan films were prepared according to previous studies by Vásconez et al. (2009) and Ojagh et al. (2010) with some modifications. Chitosan film forming solutions (CFFS) were prepared by dissolving $2 \%(\mathrm{w} / \mathrm{v})$ of chitosan in a $1 \%(\mathrm{v} / \mathrm{v})$ glacial acetic acid and homogenized with an Ultra-Turrax homogenizer (T25, Ika-Werke, Germany) at $9500 \mathrm{rpm}$ for $20 \mathrm{~min}$. The solution was kept at room temperature for $12 \mathrm{~h}$. The resultant chitosan solution was filtered through cheesecloth (non-woven) in order to remove any undissolved particles. After filtration the solution was warmed on a magnetic stirrer/hot plate $\left(40^{\circ} \mathrm{C}\right)$ and glycerol was added to a level of $0.5 \mathrm{ml} / \mathrm{g}$ chitosan as a plasticiser (Table 1 ). The plasticiser was mixed into the solution for $30 \mathrm{~min}$. Then, Tween-80 at $0.2 \%(\mathrm{v} / \mathrm{v})$ was added as an emulsifier to assist dissolution of AM agents in CFFS. The Tween- 80 was mixed into the solution for $1 \mathrm{~h}$ and after that the solutions were cooled. The AM agents were added to different chitosan solutions and mixed using an Ultra-Turrax homogenizer at $9500 \mathrm{rpm}$ for $5 \mathrm{~min}$ to reach the desired final concentration (Table 1) per film. After cooling to room temperature, the CFFS were degassed under vacuum (67 kPa) with a vacuum pump (Edwards, BS 2208, UK) for $5 \mathrm{~min}$ and then $200 \mathrm{ml}$ were casted onto $32 \mathrm{~cm}$ round glass plates, and dried for $48 \mathrm{~h}$ at ambient conditions $\left(25^{\circ} \mathrm{C}\right)$. Dried films were stored in desiccators at $25{ }^{\circ} \mathrm{C}$ and $57 \%$ relative humidity (obtained using a $\mathrm{NaBr}$ solution) until testing.

\subsection{Determination of physical properties}

\subsubsection{Film thickness}

The film thickness was determined with a digital micrometer (No. 293-5, Mitutoyo, Japan). Fifteen thickness measurements were randomly taken on each testing sample. The mean values were used to calculate WVP, $\mathrm{O}_{2} \mathrm{P}$ and $\mathrm{CO}_{2} \mathrm{P}$ and TS.

\subsubsection{Water solubility}

Water solubility was determined according to the method reported by Cuq et al. (1996). Solubility is defined as the content of dry matter solubilized after $24 \mathrm{~h}$ immersion in water. The initial dry matter content of each film was determined by drying to constant weight in an oven at $105^{\circ} \mathrm{C}$. Film disks ( $2 \mathrm{~cm}$ diameter) were cut, weighed $\left(M_{i}\right)$, and immersed in $50 \mathrm{ml}$ of water. After $24 \mathrm{~h}$ of immersion at $20^{\circ} \mathrm{C}$ with agitation $(60 \mathrm{rpm})$, the samples were taken out and dried to constant weight $\left(M_{f}\right)$ in an oven at $105^{\circ} \mathrm{C}$, to determine the weight of dry matter that was not solubilized in water. The solubility of each film was then determined as follows:

Solubility in water $(\%)=\frac{\left(M_{i}-M_{f}\right)}{M_{i}} \times 100$

where $M_{i}$ is the initial mass and $M_{f}$ is the final mass of the sample. Three replicates were obtained for each sample.

\subsubsection{Moisture content}

To determine the moisture content of films, about $50 \mathrm{mg}$ of film were dried at $105^{\circ} \mathrm{C}$ during $24 \mathrm{~h}$ (until the equilibrium weight was 
Table 1

Optimal combinations between three AM agents.

\begin{tabular}{|c|c|c|c|c|c|c|}
\hline Run $^{\mathrm{a}}$ & Carvacrol (\%) & GSE (\%) & Chitosan (\%) & Carvacrol (ppm) & GSE (ppm) & Chitosan (\% w/v) \\
\hline Film-1 & 3.2 & 34.2 & 62.6 & 9.6 & 684 & 1.25 \\
\hline Film-2 & 20 & 20 & 60 & 60 & 400 & 1.2 \\
\hline Film-3 & 30 & 8 & 62 & 90 & 160 & 1.24 \\
\hline Control & 0 & 0 & 100 & 0 & 0 & 1.25 \\
\hline
\end{tabular}

a All runs were performed in triplicate.

attained). The weight loss of the sample was determined, and moisture content was calculated using the following equation:

Moisture content $=\frac{\left(M_{i}-M_{f}\right)}{M_{i}} \times 100$

where $M_{i}$ and $M_{f}$ are the masses of initial and dried samples, respectively. Three replicates were obtained for each sample.

\subsubsection{Colour}

The films' colour was determined with a Minolta colorimeter (CR 400; Minolta, Japan). A white colour plate was used as a standard for calibration and as a background for colour measurements of the films. $L, a, b$ values of each film were evaluated by reflectance measurements (Rao et al., 2010). The measurements were repeated six times for each film.

\subsubsection{Water vapour permeability (WVP)}

The WVP was determined gravimetrically based on the ASTM E96-92 (ASTM E96-92, 1990), method and following (Cerqueira et al., 2009). The film was sealed on the top of a permeation cell containing distilled water $(100 \% \mathrm{RH} ; 2337 \mathrm{~Pa}$ vapour pressure at $20{ }^{\circ} \mathrm{C}$ ), placed in a desiccator at $20^{\circ} \mathrm{C}$ and $0 \% \mathrm{RH}(0$ Pa water vapour pressure) containing silica. The cells were weighed each $2 \mathrm{~h}$ for $10 \mathrm{~h}$. Steady-state and uniform water pressure conditions were achieved by maintaining the air circulation constant outside the test cell by using a miniature fan inside the desiccator (McHugh et al., 1993).

The WVP was estimated using regression analysis from Eq. (3) adapted from Sobral et al. (2001):

$$
\frac{W x}{A \Delta P}=W V P \times t
$$

where $x$ is the average thickness of edible films, $A$ is the permeation area $\left(0.005524 \mathrm{~m}^{2}\right), P$ is the difference of partial vapour pressure of the atmosphere $\left(2337 \mathrm{~Pa}\right.$ at $\left.20^{\circ} \mathrm{C}\right)$ and the term $w / t$ was calculated by linear regression from the points of weight gain and time, in the constant rate period. Three replicates were obtained for each sample.

\subsubsection{Fourier-transform infrared (FTIR) spectroscopy}

The infrared (IR) spectra of the films were determined with a Fourier-transform infrared spectrometer (FTIR) (Perkin Elmer 16 PC spectrometer, Boston, USA), using Attenuated Total Reflectance (ATR) mode. Each spectrum results from 16 scans at $4 \mathrm{~cm}^{-1}$ resolution for a spectral range from 650 and $4000 \mathrm{~cm}^{-1}$. All readings were performed at room temperature $\left(20^{\circ} \mathrm{C}\right)$. FTIR spectroscopy was used as a tool to investigate the interactions between chitosan and grape seed polyphenols and carvacrol by measuring the absorbance in the $650-4000 \mathrm{~cm}^{-1}$ wavenumber range at $4 \mathrm{~cm}^{-1}$ resolution.

In the case of overlapping peaks, deconvolution was performed to calculate the contribution of the individual peaks using Peakfit software version 4.12 (SYSTAT Software Inc., Richmond, CA, USA). Deconvolution was used to estimate the peak area related to the specific vibration. Spectra of films were deconvoluted with a smoothing filter of $15 \%$. Each spectrum was baseline-corrected and the absorbance was normalized between 0 and 1 .

\subsubsection{Oxygen and carbon dioxide permeabilities $\left(\mathrm{O}_{2} \mathrm{P}\right.$ and $\left.\mathrm{CO}_{2} \mathrm{P}\right)$}

$\mathrm{O}_{2} \mathrm{P}$ and $\mathrm{CO}_{2} \mathrm{P}$ were determined based on the ASTM D3985-02 (ASTM-D-3985-02, 2002) method described by (Cerqueira et al., 2009). $\mathrm{O}_{2}$ and $\mathrm{CO}_{2}$ concentrations were determined by gas chromatography (Chrompack 9001, Middleburg, Netherlands) with a column Porapak Q 80/100 mesh $2 \mathrm{~m} \times 1 / 8^{\prime \prime} \times 2 \mathrm{~mm}$ SS to separate the $\mathrm{CO}_{2}$ and with a column molecular sieve 5A 80/100 mesh $1 \mathrm{~m} \times 1 / 8^{\prime \prime} \times 2 \mathrm{~mm}$ to separate the $\mathrm{O}_{2}$ followed by a thermal conductivity detector (TCD) at $110^{\circ} \mathrm{C}$. Helium at $23 \mathrm{ml} \mathrm{min}^{-1}$ was used as carrier gas. A mixture containing $10 \% \mathrm{CO}_{2}, 20 \% \mathrm{O}_{2}$, and $70 \% \mathrm{~N}_{2}$ was used as the standard for calibration.

Three replicates were obtained for each sample, in each case $\left(\mathrm{O}_{2} \mathrm{P}\right.$ and $\left.\mathrm{CO}_{2} \mathrm{P}\right)$. For each replicate three measurements were taken.

\subsubsection{X-ray diffraction}

Films' samples were cut into circular pieces $\left(32 \mathrm{~mm}^{2}\right)$ and were mounted on a zero background silicon substrate sample holder. Samples were analysed between $2 \Theta=5^{\circ}$ and $60^{\circ}$ with a step size $2 \Theta=0.017^{\circ}$ (step time of $2000 \mathrm{~s}$ ) in a powder X-ray diffractometer X'Pert Pro PANalytical (Almelo, The Netherlands) at $45 \mathrm{kV}$ and $35 \mathrm{~mA}$, using $\mathrm{Cu} \mathrm{K} \alpha$ radiation $(\lambda=1.543 \AA$ A ) filtered by Ni. The diffractometer was equipped with an $X^{\prime}$ Celerator detector, a $0.5^{\circ}$ divergence slit and anti-scatter slits of $1^{\circ}$ and $0.5^{\circ}$ in incident and diffracted beams, respectively.

\subsection{Determination of mechanical and structural properties}

\subsubsection{Tensile strength (TS) and elongation-at-break (EB)}

$T S$ and $E B$ were measured with an Instron Universal Testing Machine (Model 4500, Instron Corporation, USA) following the guidelines of ASTM Standard Method D 882-91 (ASTM-D-882-91, 1991).

The initial grip separation was set at $30 \mathrm{~mm}$ and the crosshead speed was set at $5 \mathrm{~mm} \mathrm{~min}^{-1}$. TS was expressed in Pa and calculated by dividing the maximum load $(\mathrm{N})$ by the initial cross-sectional area $\left(\mathrm{m}^{2}\right)$ of the specimen. $E B$ was calculated as the ratio of the final length at the point of sample rupture to the initial length of a specimen $(30 \mathrm{~mm})$ and expressed as a percentage.

According to the ASTM standard, film strips with a length of $45 \mathrm{~mm}$ and a width of $20 \mathrm{~mm}$ were used. TS and $E B$ tests were replicated at least three times for each type of film.

\subsubsection{Scanning electron microscopy (SEM)}

Film surface morphology and cross section were examined using a scanning electron microscope (Nova NanoSEM 200, Netherlands) with an accelerating voltage from 10 to $15 \mathrm{kV}$. Before analysis, all samples were cut with a sharp scalpel $(3 \times 3 \mathrm{~mm})$, and were mounted on aluminium stubs using carbon adhesive tape and sputter-coated with gold (thickness of about $10 \mathrm{~nm}$ ). The energy dispersive spectroscopy analyses were performed in an integrated EDS-BSED (EDAX) system. 


\subsection{Statistical analysis}

A randomized experimental design was used. The data analyses were carried out using Statgraphics Centurion XV software (2006) using analysis of variance and Student's $t$-test. Differences were considered at a significance level of $\alpha=0.05$.

\section{Results and discussion}

\subsection{Physical and thermal properties}

\subsubsection{Thickness, water solubility and moisture content}

Homogeneous, flexible and transparent films were obtained from control and test solutions. The thin films were easily removed from the cast plate and the thickness of films varied between 0.042 and $0.062 \mathrm{~mm}$, as shown in Table 2 .

Table 2 also shows the solubility and moisture content values obtained for chitosan films. The higher solubility of the control film is attributed to the water binding capacity of plasticizer (glycerol) and functional groups of chitosan (Ojagh et al., 2010). The increase of carvacrol concentration (0-90 ppm) in mixtures with GSE and chitosan, as shown in Table 1 , leads to a significant decrease $(p<0.05)$ of moisture content values due to the hydrophobic nature of carvacrol, indicating that there was major variation of the total void volume. However, the films solubility was not affected by the incorporation of carvacrol $(p>0.05)$. Similar results were obtained by other authors when a hydrophobic agent was incorporated into chitosan films, such as $\alpha$-tocopherol or cinnamon essential oil (Martins et al., 2012; Ojagh et al., 2010). An opposite effect was observed when the GSE concentration was at the highest level (0-684 ppm) in mixtures with carvacrol and chitosan (see Table 1$)$, leading to a significant increase $(p<0.05)$ of moisture content values due to the hydrophilic nature of GSE. Although hydrophilicity of GSE and hydrophobicity of carvacrol were not characterized, carvacrol had been reported being highly hydrophobic (Burt, 2004), while the major GSE components present hydrophilic zones in their structure (Yamakoshi et al., 1999). One of the major problems of polysaccharide films is their water sensitivity, which is evaluated by different methods such as sorption and water activity, moisture content, solubility, contact angles and through the measurement of the water permeability (Martins et al., 2012). Solubility of films in water may also provide insight into the behaviour of a film in aqueous environments, being a measure of its water resistance, hence related to the hydrophilicity of the material. The moisture content is the parameter related to the total void volume occupied by water molecules in the network microstructure of the film (Pereda et al., 2011). This is also an important factor that determines biodegradability of films when used as packaging materials (Gnanasambadam et al., 1997). The resistance of films to water, determined by their solubility in the water test, is critical for the potential application of films. Sometimes, high water solubility is desired. This is the case when the film or coating will be consumed simultaneously with the food. However, in other technological applications of films, such as packaging, a low solubility in water is necessary, as is the case of packaging of highly moist foods (Rhim et al., 1998).

\subsubsection{Colour}

The colour parameters of each film are shown in Table 2. GSE (reddish in solid state) incorporation at the high level (684 ppm) into chitosan film leads to a decrease of $L$ and an increase of the $a$ parameters, indicating a decrease of the lightness and an increase of the redness of the film- 1 when compared to the control. This can be attributed to polyphenols, especially proanthocyanidins, present in GSE (Perumalla and Hettiarachchy, 2011). Siripatrawan and Harte (2010) also observed that aqueous green tea extract (high content of polyphenols like GSE) incorporated in chitosan films decreases film lightness. This property may help to avoid oxidative deterioration in packaged foods caused by exposure to visible and ultraviolet light, leading to nutrient losses, discoloration and off-flavours. The increase of the $b$ parameter in film- 1 indicates the intensification of the yellowness of the chitosan film- 1 with a significant difference $(p<0.05)$. Different results were obtained for film-3, that has a higher content of carvacrol, thus there were no significant differences in $L$ and $b$ parameters in comparison to control $(p>0.05)$.

\subsubsection{Water vapour permeability (WVP)}

The control film presented a WVP value of $(2.17 \pm 0.09) \times 10^{-7} \mathrm{~g}$ $\mathrm{Pa}^{-1} \mathrm{~s}^{-1} \mathrm{~m}^{-1}$ and similar results were obtained by Gómez-Estaca et al. (2011). The results showed that incorporation of GSE and carvacrol had a significant effect $(p<0.05)$ on WVP of chitosan films. As shown in Table 3, the increase of carvacrol in film-3 and film-2 caused a reduction of WVP. This result may be explained by the hydrophobic nature of carvacrol, which affects the hydrophilic/hydrophobic balance of the film. Similarly, Byun et al. (2010) reported that the addition of hydrophobic $\alpha$-tocopherol to polylactic acid films improved water vapour barrier properties. An opposite behaviour was observed for WVP values in film-1, probably due to the higher concentration of hydrophilic GSE in chitosan, offering more free HO-hydrophilic positions to water molecules (Vásconez et al., 2009). Additionally, the presence of GSE may originate less crystalline films, leading to an increase of the WVP. This latter hypothesis was advanced since polymer with high crystallinity are usually less permeable due their ordered structure, and therefore the mass transfer of a gas in a semicrystalline polymer occurs primarily via the amorphous phase (Sperling, 2006; Miller and Krochta, 1997).

\subsubsection{Oxygen and carbon dioxide permeabilities $\left(\mathrm{O}_{2} \mathrm{P}\right.$ and $\left.\mathrm{CO}_{2} \mathrm{P}\right)$}

The $O_{2} P$ values of the control film and of the films with GSE and carvacrol added in different proportions (film-1, film-2 and film-3) are shown in Table 3. $\mathrm{O}_{2} \mathrm{P}$ of the films increased with the incorporation of high concentration of GSE (film-1) and high concentration of carvacrol (film-2), probably due to microstructural changes in the film, becoming more porous with the addition of these agents. Film-3 and film-1 (containing high concentration of carvacrol and GSE, respectively) presented values of $O_{2} P$ of $(6.58 \pm 0.23) \times 10^{-13}$ and $(6.20 \pm 0.67) \times 10^{-13} \mathrm{~g} \mathrm{mPa}^{-1} \mathrm{~s}^{-1} \mathrm{~m}^{-2}$, respectively. These results showed a significant increase $(p<0.05)$ in the $\mathrm{O}_{2} P$ compared to the control. Similar results were obtained by Altiok et al. (2010) where films containing high concentration of thyme oil $(0.2-1.2 \%)$ increased the oxygen transmission rate. However, this effect was

Table 2

Solubility in water, moisture content and parameter of colour for different chitosan films.

\begin{tabular}{|c|c|c|c|c|c|c|}
\hline & Thickness (mm) & Solubility in water (\%) & Moisture content (\%) & $L$ & $a$ & $b$ \\
\hline Control & $0.047 \pm 0.016^{\mathrm{a}}$ & $22.74 \pm 1.82^{\mathrm{a}}$ & $6.52 \pm 2.64^{\mathrm{a}}$ & $96.19 \pm 0.69^{a, d}$ & $4.05 \pm 0.28^{a}$ & $1.06 \pm 1.04^{\mathrm{a}}$ \\
\hline Film-1 & $0.062 \pm 0.013^{b}$ & $20.53 \pm 4.96^{\mathrm{a}}$ & $14.87 \pm 1.23^{\mathrm{b}}$ & $88.05 \pm 1.91^{\mathrm{b}}$ & $8.18 \pm 0.74^{b}$ & $11.97 \pm 2.87^{b}$ \\
\hline Film-2 & $0.042 \pm 0.016^{\mathrm{a}}$ & $19.87 \pm 0.61^{\mathrm{a}}$ & $13.68 \pm 0.90^{\mathrm{bc}}$ & $93.15 \pm 2.34^{\mathrm{c}}$ & $6.39 \pm 0.58^{c}$ & $3.95 \pm 3.52^{\mathrm{a}}$ \\
\hline Film-3 & $0.042 \pm 0.017^{\mathrm{a}}$ & $18.90 \pm 3.11^{\mathrm{a}}$ & $8.87 \pm 2.04^{\mathrm{ac}}$ & $94.42 \pm 1.45$ & $5.88 \pm 0.28^{c}$ & $1.58 \pm 1.82^{\mathrm{a}}$ \\
\hline
\end{tabular}

${ }^{\mathrm{a}-\mathrm{d}}$ Different superscripts within the same column indicate significant differences between formulations $(p<0.05)$. 
Table 3

Mechanical and gas barrier properties of different chitosan films (thickness between 42 and $62 \mu \mathrm{m}$ ).

\begin{tabular}{|c|c|c|c|c|c|}
\hline & TS (MPa) & $E B(\%)$ & $W V P\left(\mathrm{~g} \mathrm{~Pa}^{-1} \mathrm{~s}^{-1} \mathrm{~m}^{-1}\right)$ & $\mathrm{O}_{2} \mathrm{P}\left(\mathrm{g} \mathrm{mPa}^{-1} \mathrm{~s}^{-1} \mathrm{~m}^{-2}\right)$ & $\mathrm{CO}_{2} \mathrm{P}\left(\mathrm{g} \mathrm{mPa}^{-1} \mathrm{~s}^{-1} \mathrm{~m}^{-2}\right)$ \\
\hline Control & $48.86 \pm 6.69^{a}$ & $28.04 \pm 9.37^{\mathrm{a}}$ & $(2.17 \pm 0.009) \times 10^{-7 a}$ & $(5.33 \pm 0.65) \times 10^{-13 a}$ & $(4.23 \pm 0.65) \times 10^{-13 a}$ \\
\hline Film-1 & $37.86 \pm 12.07^{a . b}$ & $26.79 \pm 21.93^{\mathrm{a}}$ & $(2.51 \pm 0.003) \times 10^{-7 b}$ & $(6.20 \pm 0.67) \times 10^{-13 b}$ & $(3.73 \pm 0.40) \times 10^{-13 b}$ \\
\hline Film-2 & $34.89 \pm 10.39^{a . b}$ & $27.56 \pm 13.55^{\mathrm{a}}$ & $(1.58 \pm 0.004) \times 10^{-7 c}$ & $(4.07 \pm 0.31) \times 10^{-13 c}$ & $(2.55 \pm 0.40) \times 10^{-13 c}$ \\
\hline Film-3 & $22.56 \pm 1.54^{\mathrm{b}}$ & $10.90 \pm 1.19^{a}$ & $(1.69 \pm 0.002) \times 10^{-7 d}$ & $(6.58 \pm 0.23) \times 10^{-13 b}$ & $(2.53 \pm 0.19) \times 10^{-13 c}$ \\
\hline
\end{tabular}

${ }^{a-d}$ Different superscripts within the same column indicate significant differences between formulations $(p<0.05)$.

not observed with the addition of lower concentrations of GSE and carvacrol (film-2) where a significant decrease $(p<0.05)$ in the $\mathrm{O}_{2} P$ value was obtained. The gas permeabilities are dependent on the crystallinity of the films, with $\mathrm{O}_{2} \mathrm{P}$ and $\mathrm{CO}_{2} \mathrm{P}$ decreasing with increased crystallinity (Miller and Krochta, 1997). Similar results were observed for other chitosan films where the increases of crystallinity lead to a decrease of gas permeability (Bourbon et al., 2011; Souza et al., 2009, 2010).

The $\mathrm{O}_{2} \mathrm{P}$ of food packaging materials is of great importance for food preservation, since oxygen is a key factor in oxidation, initiating several deterioration reactions (Sothornvit and Pitak, 2007). Polysaccharide films offer a good oxygen barrier, since their hydrogen-bonded network structure is tightly packed and arranged (Martins et al., 2012; Bourbon et al., 2011; Cerqueira et al., 2009).

Table 3 also shows $\mathrm{CO}_{2} \mathrm{P}$ for each film. The $\mathrm{CO}_{2} \mathrm{P}$ value obtained for the control film $\left((4.23 \pm 0.65) \times 10^{-13} \mathrm{~g} \mathrm{mPa}^{-1} \mathrm{~s}^{-1} \mathrm{~m}^{-2}\right)$ is in agreement with the results reported by other authors $\left((5.86 \pm 1.09) \times 10^{-13} \mathrm{~g} \mathrm{mPa}^{-1} \mathrm{~s}^{-1} \mathrm{~m}^{-2}\right)$ (Bourbon et al., 2011). It was found that the addition of GSE and carvacrol in different proportions into chitosan films significantly reduced $(p<0.05) \mathrm{CO}_{2} P$. This result can be attributed to the low solubility of $\mathrm{CO}_{2}$ in the films with added GSE and carvacrol. The determination of permeability of edible films to carbon dioxide provides important information for the development of edible films, especially in the design of modified atmosphere packaging (Bourbon et al., 2011; McMillin, 2008).

\subsubsection{Fourier-transform infrared (FTIR) spectroscopy}

The infrared spectra of control chitosan film and of sample films with GSE and carvacrol added in different proportions (film-1, film-2 and film-3) are shown in Fig. 1. The chitosan spectrum was similar to previous reports (Xu et al., 2005; Ritthidej et al., 2002). The peaks between 3500 and $3000 \mathrm{~cm}^{-1}$, corresponding to stretching vibration of free hydroxyl and to asymmetric and symmetric stretching of the $\mathrm{N}-\mathrm{H}$ bonds in amino group, respectively, are very similar in all films studied. The band at $1560 \mathrm{~cm}^{-1}$ corresponds to the $\mathrm{NH}$ bending (amide II vibrational mode). A small peak near to $1655 \mathrm{~cm}^{-1}$ corresponds to the $\mathrm{C}=\mathrm{O}$ stretching (amide I), and a peak at $1740 \mathrm{~cm}^{-1}$ suggested the presence of carbonyl groups. The FTIR spectra of the sample films were very similar to that the control chitosan film, as the modifier concentrations were comparatively low. Zhang and Kosaraju (2007) found that the signal from amine functional groups of chitosan decreased in presence of catechin (0.5-0.8\%). Similar findings were also observed by Siripatrawan and Harte (2010) who probed formation of covalent bonds between chitosan and green tea extract (2\%, 5\%, $10 \%$ and $20 \%$ ). No major differences in the FTIR spectra were observed; nevertheless the water barrier properties were improved for film-3 which contains more carvacrol, a hydrophobic agent, as it was already described in section of water solubility and moisture content (Section 3.1.1).

\subsubsection{X-ray diffraction}

Fig. 2 shows that the crystallinity of the chitosan films decreases with the increase of GSE in films (film-1), while increasing with the increase of carvacrol (film-3). Zhang et al. (2006) and Souza et al. (2010) have shown that the reflection around $10^{\circ}(2 \Theta)$ reflects the presence of the crystal form I and the strongest reflection at $2 \Theta=20^{\circ}$ corresponds to the crystal form II. It is known that chitosan always contains bound water $(5 \%)$ even if it has been extensively dried. The crystalline peak centred at around $10^{\circ}$ (peak I) is attributed to the hydrated crystalline structure of chitosan (Souza et al., 2010). This could confirm the decrease the crystallinity in the film-1. Another peak registered near $20^{\circ}$ (peak II) is reported to be the indication of the relatively regular crystal lattice in chitosan (Souza et al., 2010). Accordingly, the film-2 that showed the highest crystallinity in X-ray is also characterized by the lowest $\mathrm{O}_{2} \mathrm{P}$.

\subsection{Determination of mechanical properties}

\subsubsection{Mechanical properties - TS and EB}

Mechanical properties reflect the films ability to protect the physical integrity of foods (Martins et al., 2012). The effect of incorporating GSE and carvacrol in different proportions on mechanical properties of chitosan films is presented in Table 3. Control chitosan film present values of $49 \pm 7 \mathrm{MPa}$ and $28 \pm 9 \%$ for $T S$ and $E B$, respectively. These values are higher than those reported by Souza et al. (2010) ( $T S=13 \mathrm{MPa}$ and $E B=16 \%)$ and Vargas et al. (2009) ( $T S=12 \mathrm{MPa}$ and $E B=17 \%$ ). This could be due to several factors such as: chitosan composition and source, presence of a plasticizer, film preparation and storage (Martins et al., 2012; Sánchez-González et al., 2009). The carvacrol incorporation in higher concentration of GSE (film-3) showed a significant decrease on the TS of the chitosan films. A similar trend was reported by Martins et al. (2012) on chitosan films with added $\alpha$ tocopherol.

It was proposed that the addition of a hydrophobic agent to the film composition induces the development of structural discontinuities, producing a film structure with less chain mobility, and consequently, with less flexibility and resistance to fracture (Sánchez-González et al., 2009). Vargas et al. (2009) reported that incorporation of oleic acid into chitosan films decreased TS and $E B$. Similar behaviour was observed when carvacrol was added in higher concentration than GSE (film-3). Generally, oil addition to polysaccharide films decreases $T S$ and $E B$ values, once lipids are not capable to form continuous and cohesive matrices (Péroval et al., 2002). Also, the water content of the films can affect their mechanical properties. As previously mentioned, the increase of carvacrol concentration in the mixture for the chitosan film-3 decreased the water content compared with film-1 and film-2 (Table 2). Lower water content is expected to decrease film plasticity, since water also acts like a plasticizer (Rivero et al., 2010).

Regarding film-1, no significant differences were observed in TS and $E B$ values $(p>0.05)$.

\subsubsection{Scanning electron microscopy (SEM)}

Fig. 3 shows SEM micrographs of the surface and cross section of each film. Film-1 (higher concentration of GSE) showed remark- 


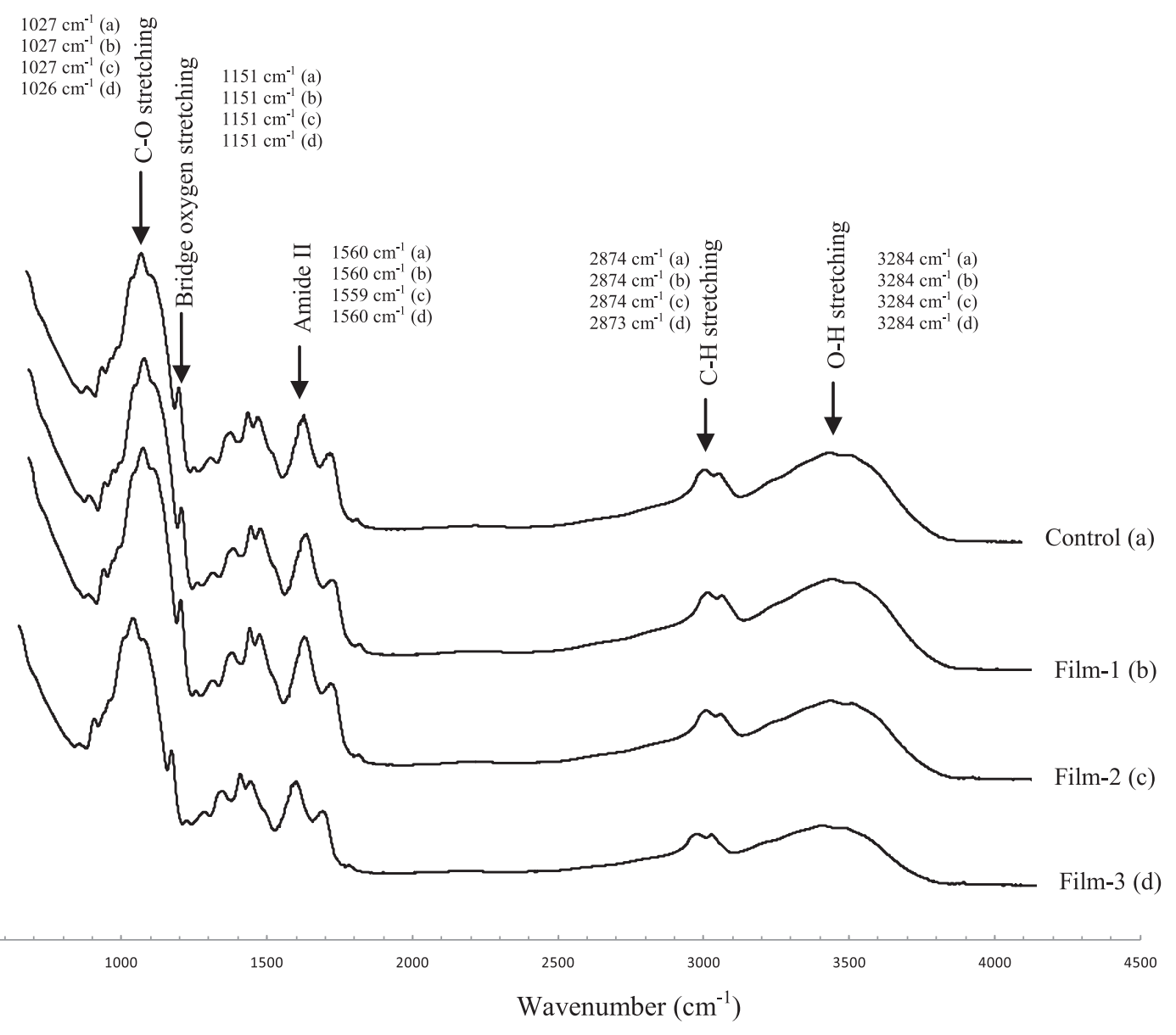

Fig. 1. Fourier transform infrared (FTIR) spectra for different chitosan films.

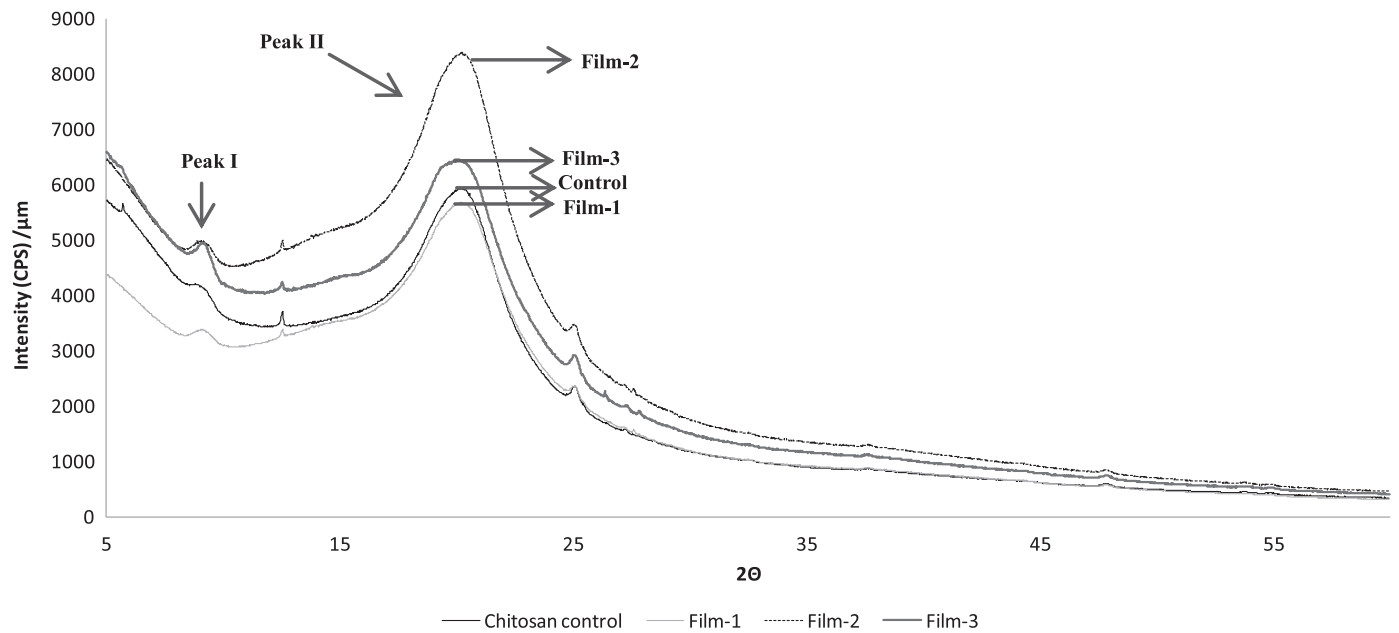

Fig. 2. X-ray diffractograms of different chitosan films, normalized to the film thickness.

able differences in terms of surface microstructure (rugous surface; Fig. 3, b.1) compared to the control film (smooth and continuous structure; Fig. 3, a.1), probably due to the hydrophilicity of GSE which may absorb higher water content. The smooth and continuous structure can be observed in the cross section of film-1 (Fig. 3, b.2). For film-2 that contains intermediate concentrations of GSE and carvacrol, showed a less rugous surface than film-1 (Fig. 3, b.1) and a more rugous surface comparing to film-3 (Fig. 3, d.1).
For film-3, that contains largest concentration of carvacrol, a hydrophobic agent, the surface view suggests a sheet-like and dense structure, while the cross section reveals the sheets stacked in compact layers (Fig. 3, d.1 and d.2). Similar result of sheets stacked with the incorporation of hydrophobic agent into chitosan matrix was observed by Ojagh et al. (2010). All cross sections (Fig. 3, b.2-d.2) showed GSE and carvacrol (in different concentrations) uniformly incorporated in the chitosan matrix. 

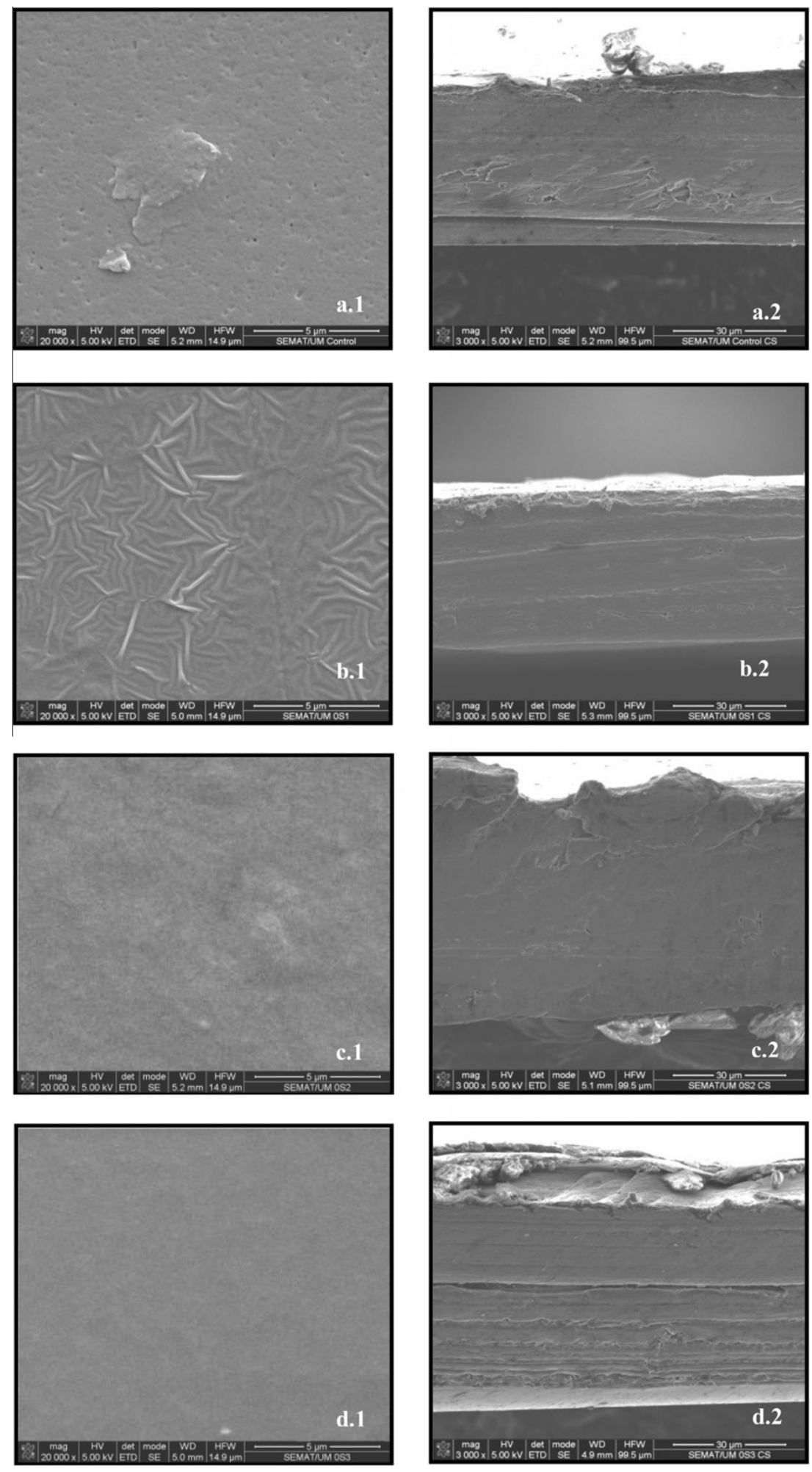

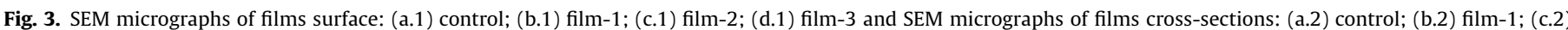
film-2; (d.2) film-3.

\section{Conclusion}

The present work shows that GSE and carvacrol mixtures can be added to a chitosan film matrix. Moreover, transparent biodegradable films were successfully prepared and the incorporation of these natural agents influenced mechanical, barrier and colour properties of the chitosan films. An increase of carvacrol concentration in the mixture (film-3) promoted a decrease of WVP, $\mathrm{CO}_{2} \mathrm{P}$, TS and $E B$ values and an increase of $\mathrm{O}_{2} \mathrm{P}$ while an increase of GSE concentration in the mixture (film-1) promoted a increase in the water content and consequently an increase in WVP and $\mathrm{O}_{2} \mathrm{P}$, and a decrease in $\mathrm{CO}_{2} \mathrm{P}$ and $\mathrm{TS}$. The incorporation of 
compounds like GSE and carvacrol can also be used to protect foods from UV light-induced degradation. Therefore, such films, used as vehicle for functional compounds, can be promising alternatives to synthetic materials, potentially contributing to improved food preservation and shelf-life extension.

\section{Acknowledgments}

The author Javiera F. Rubilar gratefully acknowledges her Ph.D. grant Erasmus Mundus 2008-1022/001 Frame ECW/17 from the EACEA of the European Union. The author Rui M. S. Cruz would like to thank Fundação para a Ciência e Tecnologia (grant SFRH/BPD/ 70036/2010).

\section{References}

Altiok, D., Altiok, E., Tihminlioglu, F., 2010. Physical, antibacterial and antioxidant properties of chitosan films incorporated with thyme oil for potential wound healing applications. Journal of Materials Science: Materials in Medicine 21 (7), 2227-2236.

Arora, D.S., Kaur, J., 1999. Antimicrobial activity of spices. International Journal of Antimicrobial Agent 12, 257-262.

ASTM E96-92, 1990. Standard Test Methods for Water Vapor Transmission of Materials. In: Annual Book of ASTM. American Society for Testing \& Materials, Philadelphia, PA.

ASTM-D-882-91, 1991. Standard Test Methods for Tensile Properties of Thin Plastic Sheeting. In: Annual Book of ASTM. American Society for Testing \& Materials, Philadelphia, PA.

ASTM-D-3985-02, 2002. Standard Test Method for Oxygen Gas Transmission Rate Through Plastic Film and Sheeting Using a Coulometric Sensor. In: Annual Book of ASTM. American Society for Testing \& Materials, Philadelphia, PA.

Baydar, N.G., Ozkan, G., Sagdic, O., 2004. Total phenolic contents and antibacterial activities of grape (Vitis Vinifera L.) extracts. Food Control 15, 335-339.

Baydar, N.G., Sagdic, O., Ozkan, G., Cetin, S., 2006. Determination of antibacterial effect and total phenolic contents of grape (Vitis vinifera) seed extract. International Journal of Food Science and Techniques 4, 799-804.

Bourbon, A.I., Pinheiro, A.C., Cerqueira, M.A., Rocha, C.M.R., Avides, M.C., Quintas, M.A.C., Vicente, A.A., 2011. Physico-chemical characterization of chitosan-based edible films incorporating bioactive compounds of different molecular weight. Journal of Food Engineering 106, 111-118.

Burt, S., 2004. Essential oils: their antibacterial properties and potential applications in foods, review. International Journal of Food Microbiology 94, 223-253.

Byun, Y., Kim, Y.T., Whiteside, S., 2010. Characterization of an antioxidant polylactic acid (PLA) film prepared with $\alpha$-tocopherol, BHT and polyethylene glycol using film cast extruder. Journal of Food Engineering 100, 239-244.

Cerqueira, M.A., Lima, A.M., Teixeira, J.A., Moreira, R.A., Vicente, A.A., 2009. Suitability of novel galactomannans as edible coatings for tropical fruits. Journal of Food Engineering 94, 372-378.

Choi, J.G., Kang, O.H., Lee, Y.S., Oh, Y.C., Chae, H.S., Jang, H.J., Shin, D.W., Kwon, D.Y., 2009. Antibacterial activity of methyl gallate isolated from galla rhois or carvacrol combined with nalidixic acid against nalidixic acid resistent bacteria. Molecules 14, 1773-1780.

Cuq, B., Gontard, N., Cuq, J.L., Guilbert, S., 1996. Functional properties of myofibrillar protein based biopackaging as affected by film thickness. Journal of Food Science 61 (3), 580-584.

Daferera, D.J., Ziogas, B.N., Polissiou, M.C., 2003. The effectiveness of plant essential oils on the growth of Botrytis cinerea, Fusarium sp. and Clavibacter michiganensis subs. Michiganensis. Crop Protection 22, 39-44.

Design-Expert Software, 2005. Version 7.0.0. Stat-Ease, Minneapolis.

Furiga, A., Lonvaud-Funel, A., Badet, C., 2009. In vitro study of antioxidant capacity and antibacterial activity on oral anaerobes of a grape seed extract. Food Chemistry 113, 1037-1040.

Gnanasambadam, R., Hettiarachchy, N.S., Coleman, M., 1997. Mechanical and barrier properties of rice bran films. Journal of Food Science 62 (2), 395-398.

Gómez-Estaca, J., Gómez-Guillén, M.C., Fernández-Martín, F., Montero, P., 2011. Effects of gelatin origin, bovine-hide and tuna-skin, on the properties of compound gelatin-chitosan films. Food Hydrocolloids 25, 1461-1469.

Guarda, A., Rubilar, J.F., Miltz, J., Galotto, M.J., 2011. The antimicrobial activity of microencapsulated thymol and carvacrol. International Journal of Food Microbiology 146, 144-150.

Gutierrez, J., Barry-Ryan, C., Bourke, P., 2009. Antimicrobial activity of plant essential oils using food model media: efficacy, synergistic potential and interactions with food components. Food Microbiology 26, 142-150.

Holley, R.A., Patel, D., 2005. Improvement in shelf-life and safety of perishable foods by plant essential oils and smoke antimicrobials, a review. Food Microbiology 22, 273-292.

Hosokawa, J., Nishiyama, M., Yoshihara, K., Kubo, T., 1990. Biodegradable film derived from chitosan and homogenized cellulose. Industrial and Engineering Chemistry Research 29 (5), 800-805.

Jayaprakasha, G.K., Selvi, T., Sakariah, K.K., 2003. Antibacterial and antioxidant activities of grape (Vitis vinifera) seed extract. Food Research International 6, 117-122.
Kulisic, T., Radonic, A., Katalinic, V., Milos, M., 2004. Use of different methods for testing antioxidative activity of oregano essential oil. Food Chemistry 85, 633640.

Lagouri, V., Blekas, G., Tsimidou, M., Kokkini, S., Boskou, D., 1993. Composition and antioxidant activity of essential oils from oregano plants grown wild in Greece. Zeitschrift fur Lebensmittel-Unter suchung und -Forschung A 197, 20-23.

Lee, D.S., 2005. Packaging containing natural antimicrobial or antioxidative agents. In: Han, J. (Ed.), Innovations in Food Packaging. Elsevier Science \& Technology Books, pp. 108-119.

Martínez-Romero, D., Guillén, F., Valverde, J. M., Bailén, G., Zapata, P., Serrano, Castillo, S., Valero, D., 2007. Influence of carvacrol on survival of Botrytis cinerea inoculated in table grapes. International Journal of Food Microbiology, 115, 144-148.

Martins, J.T., Cerqueira, M.A., Vicente, A.A., 2012. Influence of $\alpha$-tocopherol on physicochemical properties of chitosan-based films. Food Hydrocolloids 27 (1), 220-227.

McHugh, T.H., Avena-Bustillos, R.J., Krochta, J.M., 1993. Hydrophilic edible film: modified procedure for water vapor permeability and explanation of thickness effects. Journal of Food Science 58 (4), 899-903.

McMillin, K.W., 2008. Where is MAP going? A review and future potential of modified atmosphere packaging for meat. Meat Science 80 (1), 43-65.

Miller, K.S., Krochta, J.M., 1997. Oxygen and aroma barrier properties of edible films: a review. Trends in Food Science and Technology 8 (7), 228-237.

Monagas, M., Gómez-Cordovés, C., Bartolomé, B., Laureano, O., Ricardo da Silva, J.M., 2003. Monomeric, oligomeric, and polymeric flavan-3-ol composition of wines and grape from Vitis vinifera L. Cv. Graciano, Tempranillo, and Cabernet Sauvignon. Journal of Agricultural and Food Chemistry 51, 6475-6481.

Ojagh, S.M., Rezaei, M., Razavi, S.H., Hosseini, S.M.H., 2010. Development and evaluation of a novel biodegradable film made from chitosan and cinnamon essential oil with low affinity toward water. Food Chemistry 122, 161-166.

Park, S.I., Zhao, Y., 2004. Incorporation of a high concentration of mineral or vitamin into chitosan-based films. Journal of Agricultural and Food Chemistry 52 (7), 1933-1939.

Pereda, M., Ponce, A.G., Marcovich, N.E., Ruseckaite, R.A., Martucci, J.F., 2011. Chitosan-gelatin composites and bi-layer films with potential antimicrobial activity. Food Hydrocolloids 25, 1372-1381.

Periago, P.M., Delgado, B., Fernández, P.S., Palop, A., 2004. Use of carvacrol and cymene to control growth and viability of Listeria monocytogenes cells and predictions of survivors using frequency distribution functions. Journal of Food Protection 67, 1408-1416.

Péroval, C., Debeaufort, F., Despre, D., Voilley, A., 2002. Edible arabinoxylanbased films. 1. Effects of lipid type on water vapor permeability, film structure, and other physical characteristics. Journal of Agricultural and Food Chemistry 50, 3977-3983.

Perumalla, A.V.S., Hettiarachchy, N.S., 2011. Green tea and grape seed extracts Potential applications in food safety and quality, Review. Food Research International 44 (4), 827-839.

Rao, M.S., Kanatt, S.R., Chawla, S.P., Sharmam, A., 2010. Chitosan and guar gum composite films: preparation, physical, mechanical and antimicrobial properties. Carbohydrate Polymers 82 (4), 1243-1247.

Rhim, J.W., Weller, C.L., Ham, K.S., 1998. Characteristics of chitosan films as affected by type of solvent acid. Food Science and Biotechnology 7 (4), 263-268.

Ritthidej, G.C., Thawatchai, P., Koizumi, T., 2002. Moist heat treatment on physicomechanical change of chitosan salt films. International Journal of Pharmaceutics 232, 11-22.

Rivero, S., García, M.A., Pinnoti, A., 2010. Correlations between structural, barrier, thermal and mechanical properties of plasticized gelatin films. Innovative Food Science and Emerging Technologies 11 (2), 369-375.

Rodríguez, F.J., Galotto, M.J., Guarda, A., Bruna, J.E., 2012. Modification of cellulose acetate films using nanofillers based on organoclays. Journal of Food Engineering 110 (2), 262-268.

Rubilar, J.F., Cruz, R.M.S., Khmelinskii, I., Vieira, M.C., 2012. Antioxidant and optimal antimicrobial mixtures of carvacrol, grape seed extract and chitosan on different spoilage microorganisms and their application in different food matrices. International Journal of Food Studies. accepted for publication.

Rudnik, E., 2008. Compostable Polymer Materials. Elsevier, Amsterdam, pp 7

Sánchez-González, L., Vargas, M., González-Martínez, C., Chiralt, A., Cháfer, M., 2009. Characterization of edible films based on hydroxypropylmethylcellulose and tea tree essential oil. Food Hydrocolloids 23 (8), 2102-2109.

Siripatrawan, U., Harte, B.R., 2010. Physical properties and antioxidant activity of an active film from chitosan incorporated with green tea extract. Food Hydrocolloids 24, 770-775.

Sivropoulou, A., Papanikolaou, E., Nikolaou, C., Kokkini, S., Lanaras, T., Arsenakis, M., 1996. Antimicrobial and cytotoxic activities of Origanum essential oils. Journal of Agricultural and Food Chemistry 44, 1202-1205.

Sobral, P.J.A., Menegalli, F.C., Hubinger, M.D., Roques, M.A., 2001. Mechanical, water vapor barrier and thermal properties of gelatin based edible films. Food Hydrocolloids 15, 423-432.

Sothornvit, R., Pitak, N., 2007. Oxygen permeability and mechanical properties of banana films. Food Research International 40 (3), 365-370.

Souza, B.W.S., Cerqueira, M.A., Casariego, A., Lima, A.M.P., Teixeira, J.A., Vicente, A.A., 2009. Effect of moderate electric fields in the permeation properties of chitosan coatings. Food Hydrocolloids 23 (8), 2110-2115.

Souza, B.W.S., Cerqueira, M.A., Martins, J.T., Casariego, A., Teixeira, J.A., Vicente, A.A., 2010. Influence of electric fields on the structure of chitosan edible coatings. Food Hydrocolloids 24 (4), 330-335. 
Sperling, L.H., 2006. Introduction to Physical Polymer Science, fourth ed. John Wiley and Sons, Inc., New Jersey.

Statgraphics Centurion XV Software, 2006. Version 15.2. 05. Statistical Graphics Corp., Warrenton, Virginia.

Tripathi, S., Mehrotra, G.K., Dutta, P.K, 2009. Physicochemical and bioactivity of cross-linked chitosan-PVA film for food packaging applications. International Journal of Biological Macromolecules 45, 372-376.

Vargas, M., Albors, A., Chiralt, A., González-Martínez, C., 2009. Characterization of chitosan-oleic acid composite films. Food Hydrocolloids 23 (2), 536-547.

Vásconez, M.B., Flores, S.K., Campos, C.A., Alvarado, J., Gerschenson, L.N., 2009. Antimicrobial activity and physical properties of chitosan-tapioca starch based edible films and coatings. Food Research International 42, 762-769.
Xu, Y.X., Kim, K.M., Hanna, M.A., Nag, D., 2005. Chitosan-starch composite film: preparation and characterization. Industrial Crops and Products 21 (2), 185192.

Yamakoshi, J., Kataoka, S., Koga, T., Ariga, T., 1999. Proanthocyanidin-rich extract from grape seeds attenuates the development of aortic atherosclerosis in cholesterol-fed rabbits. Atherosclerosis 142, 139-149.

Zhang, C., Ding, Y., Ping, Q., Yu, L.L., 2006. Novel chitosan-derived nanomaterials and their micelle-forming properties. Journal of Agriculture and Food Chemistry 54, 8409-8416.

Zhang, L., Kosaraju, S.L., 2007. Biopolymeric delivery system for controlled release of polyphenolic antioxidants. European Polymer Journal 43, 2956-2966. 